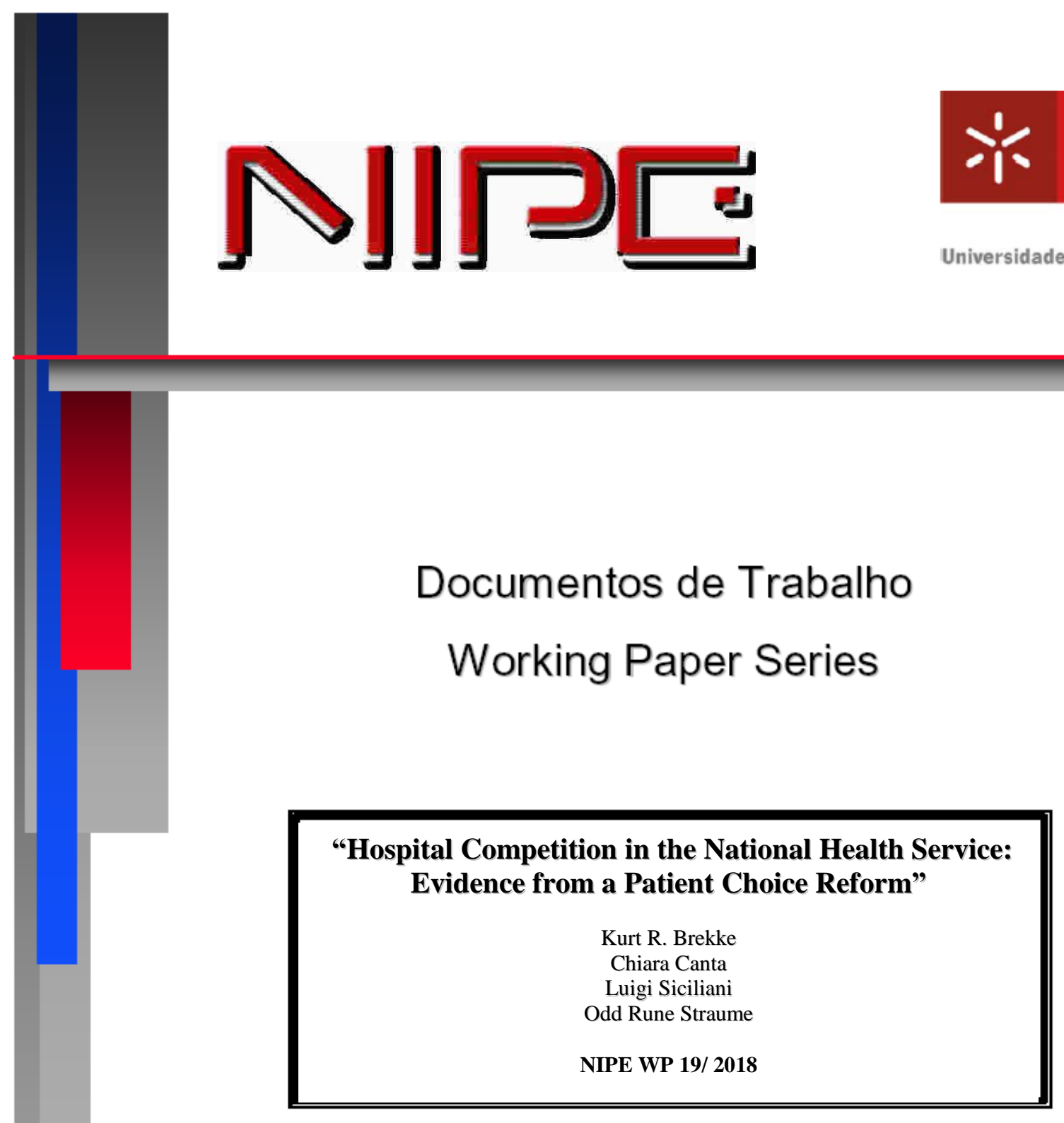

NÚCLEO DE INVESTIGAÇÃO EM POLÍTICAS ECONÓMICAS UNIVERSIDADE DO MINHO 


\section{"Hospital Competition in the National Health Service: Evidence from a Patient Choice Reform"}

Kurt R. Brekke

Chiara Canta

Luigi Siciliani

Odd Rune Straume

\section{NIPE* W19/2018}

URL:

http://www.nipe.eeg.uminho.pt/

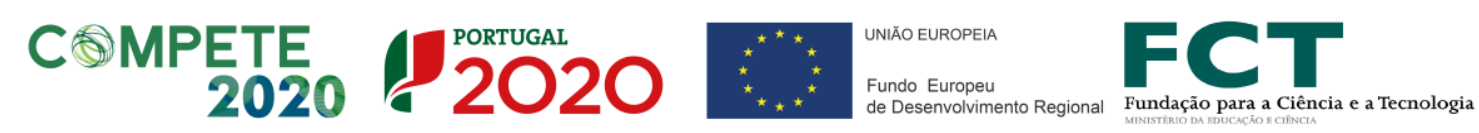

"This work was carried out within the funding with COMPETE reference no POCI-01-0145-FEDER-006683 (UID/ECO/03182/2013), with the FCT/MEC's (Fundação para a Ciência e a Tecnologia, I.P.) financial support through national funding and by the ERDF through the Operational Programme on "Competitiveness and Internationalization - COMPETE 2020 under the PT2020 Partnership Agreement» 


\title{
Hospital Competition in the National Health Service: Evidence from a Patient Choice Reform*
}

\author{
Kurt R. Brekke ${ }^{\dagger} \quad$ Chiara Canta $^{\ddagger} \quad$ Luigi Siciliani $^{\S} \quad$ Odd Rune Straume
}

December 13, 2018

\begin{abstract}
We study the impact of exposing hospitals in a National Health Service (NHS) to non-price competition by exploiting a patient choice reform in Norway in 2001. The reform facilitates a difference-in-difference research design due to geographical variation in the scope for competition. Using rich administrative data covering the universe of NHS hospital admissions from 1998 to 2005, we find that hospitals in more competitive areas have a sharper reduction in AMI mortality, readmissions, and length of stay than hospitals in less competitive areas. These results indicate that competition improves patient health outcomes and hospital cost efficiency, even in the Norwegian NHS with large distances, low fixed treatment prices, and mainly public hospitals.
\end{abstract}

Keywords: Patient Choice; Hospital Competition; Quality; Cost-efficiency

JEL Classification: I11; I18; L13

\footnotetext{
*This paper is written as a part of the SNF project Competition in Hospital Markets (no. 9040) funded by Prisreguleringsfondet administrated by the Norwegian Competition Authority. Odd Rune Straume also acknowledges funding from COMPETE (POCI-01-0145-FEDER-006683), with the FCT/MEC's financial support through national funding and by the ERDF through the Operational Programme on Competitiveness and Internationalization - COMPETE 2020 under the PT2020 Partnership Agreement.

${ }^{\dagger}$ Corresponding author. Norwegian School of Economics (NHH), Department of Economics, Helleveien 30,5045 Bergen, Norway; and Centre for Applied Research at NHH. E-mail: kurt.brekke@nhh.no

${ }^{\ddagger}$ Toulouse Business School, 1M Place Alphonse Jourdain, 31068 Toulouse, France. E-mail: c.canta@tbseducation.fr.

${ }^{\S}$ University of York, Department of Economics and Related Studies, York YO10 5DD, UK; and C.E.P.R., 90-98 Goswell Street, London EC1V 7DB, UK. E-mail: luigi.siciliani@york.ac.uk.

๑University of Minho, Department of Economics/NIPE, Campus de Gualtar, 4710-057 Braga, Portugal; and University of Bergen, Department of Economics. E-mail: o.r.straume@eeg.uminho.pt.
} 


\section{Introduction}

Health care is one of the most important sectors in the economy. OECD countries spend on average 9 percent of their GDP on health care (OECD, 2017). Health care is also crucial for individuals' well-being and the health status of the population more broadly. The organisation of health care provision is therefore of great importance.

The health care sector has traditionally been, and still is, extensively regulated in many countries, implying limited, or in some countries even no use of market mechanisms. ${ }^{1}$ This has particularly been the case in countries with a National Health Service (NHS), such as the UK, the Scandinavian countries, and the Southern European countries. In the last decades, however, many countries, including countries with an NHS, have introduced market-oriented reforms introducing provider competition in the delivery of health care.

Despite the extensive adoption of market-oriented reforms across countries, there is still lack of strong evidence on the impact of introducing competition in the provision of health care, especially from outside the US and England. ${ }^{2}$ Most of the existing studies, which are based on the US Medicare programme, exploit cross-sectional variation in market structure to identify the impact of competition. A potential problem with this approach is that market structure is not exogenous, but possibly affected by hospital performance along dimensions such as quality of care. ${ }^{3}$

To address this issue, we follow the approach proposed by Cooper et al. (2011) and Gaynor et al. (2013), who study the impact of hospital competition by exploiting an exogenous policy reform introducing patient choice in the English NHS in 2006. While the reform applied to all NHS hospitals at the same time, geographical variation in market structure prior to the reform facilitates a difference-in-difference (DiD) research design. In Norway there was a similar reform in 2001, where the government introduced nationwide patient choice within the Norwegian NHS, replacing an administrative system where patients were referred to the closest hospital offering the relevant treatment within their county of residence. The new policy therefore implied a switch from a situation where the NHS hospitals were local monopolists in their catchment area to a scheme with potential for non-price competition among NHS hospitals.

While the policy reforms introducing patient choice in the English and the Norwegian NHS are

\footnotetext{
${ }^{1}$ There are notable exceptions, such as the US where market mechanisms for the delivery of health care have been in place for a long time.

${ }^{2}$ See Gaynor and Town (2011) for an extensive overview of the literature on competition in health care markets.

${ }^{3}$ High-quality hospitals are likely to have a larger market share (more patients) than low-quality hospitals. The presence of a high-quality hospital may also deter entry of new hospitals into the market.
} 
fairly similar, there are also important differences across the two NHS systems. First, England had a gradual roll-out of their fixed price (Payment by Result) funding scheme in the period prior to the reform, with the full scale implementation of this scheme coinciding with the patient choice reform. ${ }^{4}$ In Norway, however, a fixed price payment scheme based on diagnosis related groups (DRG) was in place since 1997 and did not change before (or after) the policy reform. Second, while England implemented a pure fixed price scheme, Norway had a mixed payment scheme which was partly based on fixed prices and partly on block grants. The fixed price component accounted for about 40-60\% of hospital revenues, with the remaining being covered by the block grant. An important implication of this is that Norwegian NHS hospitals were facing much lower fixed treatment prices than their English counterparts, potentially reducing their incentives to compete. Third, whereas NHS hospitals in England are organised as free-standing trusts (mostly as Foundation Trusts with discretion to retain and utilise financial surpluses), the Norwegian NHS hospital market is composed of both public and private (non-profit) hospitals, with the former constituting the vast majority (around 90 percent). Finally, a quick glance at the map reveals that travel distances are substantially larger in Norway than in England, which potentially implies lower competitive pressures for Norwegian hospitals. The contribution of our study is therefore to provide more evidence on the causal effects of hospital competition from outside the US and England, in a setting where relevant institutional differences are potentially important, thus contributing to the external validity of the findings in the existing literature.

In order to do so, we have assembled a rich dataset based on detailed administrative data covering the universe of hospital admissions in the Norwegian NHS over eight years from 1998 to 2005. For the analysis, the data are aggregated to quarterly observations at hospital and DRG level. We use a similar DiD research design as Cooper et al. (2011) and Gaynor et al. (2013), where the post-reform period is interacted with a treatment (competition) intensity variable specific for each hospital. This implies that the impact of hospital competition is identified by comparing the differential effects between hospitals in less competitive areas with hospitals in more competitive areas before and after the reform. Treatment (competition) intensity is captured by a HirschmanHerfindahl Index (HHI) for each hospital based on predicted patient flows prior to the reform to account for endogenous market structure, as in Gaynor et al. (2013). ${ }^{5}$ The effects of exposing

\footnotetext{
${ }^{4}$ See Gaynor et al. (2013) for a more detailed description of the roll-out of the Payment by Result scheme in the English NHS.

${ }^{5}$ Cooper et al. (2011) use also HHIs based on predicted patient flows, but compute these for each period, including periods after the patient choice reform.
} 
the NHS hospitals to competition are estimated controlling for time trends, patient case mix (age, gender, comorbidities) at hospital and DRG level, and hospital and DRG fixed effects.

Based on the DiD approach, we obtain the following results. First, we find that the introduction of (non-price) competition in the Norwegian NHS, induced by the patient choice reform, is associated with a sharper decline in acute myocardial infarction (AMI) mortality rates for hospitals in more competitive (less concentrated) areas compared to hospitals in less competitive (more concentrated) areas. A 10 percent reduction in the average HHI leads to a 2.8 percent (or 0.4 percentage point) fall in the AMI mortality rate. The point estimates of the effect of competition on stroke and overall hospital mortality have the same sign as the effect on AMI mortality, but these estimates are not statistically significant. These pro-competitive findings on hospital quality are similar, also in terms of magnitude, to the findings by Cooper et al. (2011) and Gaynor et al. (2013) from the English NHS. This is perhaps surprising, given that the Norwegian health care system is characterised by lower fixed (DRG) prices due to partial block grant funding, publicly owned hospitals (which might imply less profit orientation) and generally longer travel distances, which in sum suggest a smaller scope for competition.

Second, we find that the introduction of competition in the Norwegian NHS is associated with a sharper reduction in (elective and emergency) readmission rates for hospitals in more competitive areas compared to hospitals in less competitive areas after the reform. A readmission usually reflects that the first treatment was associated with complications, implying that lower readmission rates signal higher hospital quality. Thus, this finding supports the pro-competitive results for AMI mortality. Although the patient choice reform only applied to elective treatments, the effect on readmission rates is even stronger for emergency treatments, which suggests a positive spillover effect on emergency treatments of exposing NHS hospitals to competition. As the results for elective readmissions may potentially be biased due to changes in patient flows induced by the patient choice reform, it is reassuring that the effects for emergency treatments are qualitatively similar. Cooper et al. (2011) and Gaynor et al. (2013) do not consider the effects on hospital readmissions.

Third, we find that the patient choice reform induced a sharper decline in length of stay at NHS hospitals in more competitive areas compared to NHS hospitals in less competitive areas, indicating a pro-competitive effect on hospital cost efficiency. As for readmissions, the effects are statistically significant for both elective and emergency treatments, suggesting a positive spillover effect of 
the patient choice reform on emergency treatments. We also find some evidence of differential ownership effects of competition, where the effect of competition on cost efficiency tends to be significantly stronger for private (non-profit) hospitals than for the public hospitals. It must be stressed, though, that these results are based on the observed responses of only six private hospitals, and should therefore be interpreted with some caution. Cooper et al. (2011) and Gaynor et al. (2013) find similar effects on length of stay, but do not investigate possible differential effects of ownership or for elective vs. emergency treatments.

We rationalise the above described findings in a theoretical analysis, showing that the effects of (non-price) competition, induced by patient choice, on hospital quality and cost efficiency depend on hospitals' profit orientation and price-cost margins. In particular, if hospitals are profit oriented and face positive price-cost margins, competition will improve both hospital quality and cost efficiency. However, if hospitals are less profit oriented (more altruistic) and face negative price-cost margins, then competition has in general ambiguous effects on hospital quality and cost efficiency. Since hospitals in the Norwegian NHS are mainly public and the fixed (DRG) prices are low due to a mixed funding scheme, it is far from obvious that the introduction of competition would have positive quality and cost efficiency effects. However, our empirical analysis identifies, as in the English NHS, pro-competitive effects of the patient choice reform.

In summary, our study provides evidence that exposing NHS hospitals to non-price competition saves lives, reduces complications, and shortens hospital stays, which suggests that competition improves patient welfare and possibly also total welfare. In order to illustrate the magnitudes of these effects, consider as a simple example an increase in the number of competing hospitals from two to three, which - assuming symmetry - reduces the HHI by 33 percent. At the sample means, this increase in competition implies that one life is saved per 77 AMI admissions, that there is one less readmission per 23 (150) emergency (elective) admissions, and that one in every 14 (4) emergency (elective) patients is discharged from hospital one day earlier.

In qualitative terms, our findings are consistent with evidence from the English NHS provided by Cooper et al. (2011) and Gaynor et al. (2013), but also with several US studies focusing on the provision of hospital care to Medicare patients where prices are also fixed, e.g., Kessler and McClellan (2000). Our study of the Norwegian NHS therefore extends the robustness and thus the external validity of the positive effects of exposing hospitals to non-price competition in an institutional setting where hospitals' incentives to compete appear to be relatively weak. 
The rest of the paper is organised as follows. In Section 2 we explain in more detail the relation of our study to existing literature. In Section 3 we present a general theoretical framework to study how hospital competition is likely to affect quality provision and cost efficiency. In Section 4 we explain the institutional setting and the policy reforms of the Norwegian NHS, whereas data and descriptive statistics are presented in Section 5. In Section 6 we describe our empirical strategy which produces the results that are presented in Section 7. Finally, some concluding remarks are offered in Section 8.

\section{Related literature}

Our paper relates primarily to the empirical literature on the impact of competition in hospital markets. ${ }^{6}$ The evidence on the effect of competition is mostly from the US and the UK, and has mixed findings. In the US, Kessler and McClellan (2000) find that AMI mortality is higher for Medicare patients in more concentrated markets. ${ }^{7}$ They also find that hospitals in less concentrated areas have lower expenditures when Medicare introduced fixed (DRG) prices, and conclude that (non-price) competition among US hospitals is welfare improving. Shen (2003) finds that competition (measured by the number of hospitals) interacted with the Medicare payment leads to lower AMI mortality for Medicare patients after 1990. In contrast, Gowrisankaran and Town (2003) find that AMI and pneumonia mortality rates are higher for Medicare patients in less concentrated markets in the Los Angeles area. Mukamel et al. (2001) find no effect of competition (measured by concentration) on overall hospital mortality for Medicare patients. A recent study by Colla et al. (2016) finds that competition reduces AMI mortality, has no effect on emergency readmissions for hip and knee replacement, and reduces quality for dementia patients in Medicare. ${ }^{8}$

In England, Propper et al. (2004) and Burgess et al. (2008) find that more competition increased AMI mortality in the 1990s when the internal market was introduced and hospital prices were not fixed but negotiated with local health authorities. Burgess et al. (2008), however, find that

\footnotetext{
${ }^{6}$ There is also a large theoretical literature on hospital competition. Gaynor (2006) shows that profit-maximising hospitals respond to competition by improving quality of care when prices are fixed, while this effect is generally ambiguous with endogenous prices. Brekke et al. (2011) show that the positive effect of hospital competition on quality with fixed prices holds also for semi-altruistic hospitals unless the degree of altruism is sufficiently high. See also Brekke et al. (2010) for a study on quality competition with endogenous prices.

${ }^{7}$ In a related paper, Kessler and Geppert (2005) find that the AMI mortality rate for high-risk Medicare patients is higher in concentrated markets, while there is no such effect for low-risk patients.

${ }^{8}$ There is also an interesting strand of literature on the interaction between information and competition in hospital markets. For example, Chou et al. (2014) find that report cards on the quality of providers reduced CABG mortality for more severely ill patients in more competitive areas.
} 
competition did significantly reduce waiting times, and this may be due to purchasers negotiating mostly on waiting times rather than on clinical quality. The most recent empirical literature from England finds that competition increases quality. Bloom et al. (2015) instrument for competition with the marginality of local Parliamentary seats and find that hospitals in more competitive areas had lower AMI mortality. Cooper et al. (2011) and Gaynor et al. (2013) find, as mentioned previously, that hospitals in more competitive areas had sharper reductions in AMI mortality following the patient choice reform of 2006. Moscelli et al. (2018) also found that competition reduced hip fracture mortality, but not stroke mortality. Gaynor et al. (2013) found that it reduced length of stay but did not affect expenditure or volume of admissions. Feng et al. (2015) find that competition is positively associated with health gains for hip replacement patients, where the health gain is measured by the difference in patient reported health outcomes (PROMs) before and after the surgery. Cooper et al. (2016) find that the entry of a private hospital in the NHS market reduced pre-operative length of stay for hip and knee replacement patients. For Italy, Berta et al. (2016) find that competition does not affect quality.

The contribution of our study to this literature is two-fold. First, we contribute to the existing literature by providing causal evidence on the impact of hospital competition by exploiting an exogenous policy reform in the Norwegian NHS, taking the same approach as Cooper et al. (2011) and Gaynor et al. (2013). This approach deals with the endogeneity of market structure that possibly affects the estimates in studies using cross-sectional variation in market concentration over time. Second, our study confirms the external validity of the aforementioned estimated effects of hospital competition by providing evidence from outside the US and England. Compared to the US, the institutional setting in the Norwegian NHS is very different along many dimensions, including ownership structure, use of market mechanisms, extent of endogenous versus fixed prices, etc. Compared to the English NHS, the institutional setting in the Norwegian NHS is also different along a few dimensions, including the level of the fixed prices, the ownership structure, and the geographic distribution of hospitals and patients. Despite low fixed (DRG) prices, public hospitals, and long travel distances, we still find positive effects of competition on hospital quality and cost efficiency, indicating a welfare improvement of the reorganisation of the delivery of health care. In the next section, we present mechanisms that might possibly explain these findings. 


\section{Theoretical framework}

Suppose that there are two hospitals, denoted by subscripts $i$ and $j$, in a given market for secondary health care. ${ }^{9}$ Patients are fully insured against health expenses, so the demand for Hospital $i$, measured by number of treatments, is given by $x_{i}\left(q_{i}, q_{j}, \theta\right)$, where $q_{k} \geq \underline{q}$ is the quality of Hospital $k=i, j$. The lower bound on hospital quality represents the minimum treatment quality that hospitals are allowed to offer, implying that $q<\underline{q}$ can be interpreted as malpractice. We assume that $x_{i}$ is increasing in $q_{i}$ and decreasing in $q_{j}$. The effect of competition is captured by the parameter $\theta$, which measures the degree of patient choice, implying that a higher value of $\theta$ represents a market with more competition. We assume that $\partial x_{i} / \partial \theta>(<) 0$ if $q_{i}>(<) q_{j}$, and that $\partial x_{i} / \partial \theta=0$ if $q_{i}=q_{j}$. Thus, for a given distribution of qualities across hospitals, patient choice increases (reduces) demand for hospitals with higher (lower) quality. Furthermore, we assume that $\partial^{2} x_{i} / \partial \theta \partial q_{i}>0$, implying that patient choice makes demand for each hospital more responsive to quality changes. This is, intuitively, the key effect of competition in markets where the providers compete on quality.

The objective function of Hospital $i$ is assumed to be given by

$$
\pi_{i}=T+p x_{i}\left(q_{i}, q_{j}, \theta\right)-c\left(x_{i}\left(q_{i}, q_{j}, \theta\right), q_{i}, e_{i}\right)+\alpha B_{i}\left(x_{i}\left(q_{i}, q_{j}, \theta\right), q_{i}\right)-g\left(e_{i}\right) .
$$

The hospital payment system is characterised by the contract $(p, T)$, where each hospital receives a fixed price $p$ per treatment and a lump-sum payment $T$. Total treatment costs are given by a cost function $c(\cdot)$ which depends on the total number of treatments $\left(x_{i}\right)$, quality $\left(q_{i}\right)$ and the amount of cost-containment effort $\left(e_{i}\right)$ exerted by the hospital. ${ }^{10}$

We assume that, by spending more effort on cost containment, the hospital can (i) reduce the total costs of a given treatment volume and quality provision $\left(\partial c / \partial e_{i}<0\right)$, (ii) reduce the marginal cost of treatments $\left(\partial^{2} c / \partial e_{i} \partial x_{i}<0\right)$ for a given quality level and (iii) possibly also reduce the marginal cost of quality provision for a given treatment volume $\left(\partial^{2} c / \partial e_{i} \partial q_{i} \leq 0\right)$. The disutility of exerting cost-containment effort is given by a strictly convex function $g\left(e_{i}\right)$.

We also assume that the providers are semi-altruistic in the sense that patient utility is part of the hospitals' objectives. More specifically, we assume that the decision-makers at Hospital $i$ to

\footnotetext{
${ }^{9}$ As long as the market is symmetric, the analysis can easily be extended to $n$ hospitals. However, only two hospitals are needed in order to illustrate all the potential mechanisms at play.

${ }^{10}$ In reality, a hospital's quality and cost efficiency are likely to result from choices made by different decision makers (e.g., managers and doctors) whose objectives might not be perfectly aligned. We take a standard black-box approach and assume that the objective function (1) is an aggregation of the objectives of all relevant decision makers within the hospital.
} 
some extent take into account the total utility of patients treated at the hospital, given by $B_{i}(\cdot)$, which is increasing in $x_{i}$ and $q_{i}$. The degree of altruism is captured by the parameter $\alpha$, implying that a purely profit-oriented hospital is characterised by $\alpha=0$.

Suppose that the two hospitals play a non-cooperative game where they simultaneously choose quality and cost-containment effort. The first-order conditions for Hospital $i$ are given by

$$
\begin{gathered}
\frac{\partial \pi_{i}}{\partial q_{i}}=p \frac{\partial x_{i}}{\partial q_{i}}-\frac{\partial c}{\partial x_{i}} \frac{\partial x_{i}}{\partial q_{i}}-\frac{\partial c}{\partial q_{i}}+\alpha\left(\frac{\partial B_{i}}{\partial x_{i}} \frac{\partial x_{i}}{\partial q_{i}}+\frac{\partial B_{i}}{\partial q_{i}}\right)=0 \\
\frac{\partial \pi_{i}}{\partial e_{i}}=-\frac{\partial c}{\partial e_{i}}-\frac{\partial g}{\partial e_{i}}=0
\end{gathered}
$$

We consider a symmetric equilibrium with interior solutions, where $q_{j}=q_{i}>\underline{q}$ and $e_{j}=e_{i}>0$. The Nash equilibrium is then characterised by the following 2-equation system:

$$
\begin{aligned}
& F_{q}:=\left.\frac{\partial \pi_{i}}{\partial q_{i}}\right|_{q_{j}=q_{i}, e_{j}=e_{i}}=0, \\
& F_{e}:=\left.\frac{\partial \pi_{i}}{\partial e_{i}}\right|_{q_{j}=q_{i}, e_{j}=e_{i}}=0 .
\end{aligned}
$$

\subsection{Competition and quality provision}

From (4)-(5), we derive the following relationship between patient choice and equilibrium quality provision (see Appendix A for details):

$$
\frac{\partial q_{i}}{\partial \theta}>(<) 0 \quad \text { if } \quad p-\frac{\partial c}{\partial x_{i}}+\alpha \frac{\partial B_{i}}{\partial x_{i}}>(<) 0
$$

An effect (positive or negative) of competition on equilibrium quality provision requires that the equilibrium is an interior solution with $q_{i}>\underline{q}$. Thus, the condition in (6) needs to be seen in conjunction with the first-order condition for optimal quality provision, given by (2). ${ }^{11}$ For this purpose, it is useful to re-write (2) as follows:

$$
\left(p-\frac{\partial c}{\partial x_{i}}+\alpha \frac{\partial B_{i}}{\partial x_{i}}\right) \frac{\partial x_{i}}{\partial q_{i}}+\alpha \frac{\partial B_{i}}{\partial q_{i}}=\frac{\partial c}{\partial q_{i}}
$$

\footnotetext{
${ }^{11}$ These conditions represent a generalised version of the main result derived in Brekke et al. (2011), where competition is explicitly modelled as a switch from local monopolies to localised competition in a spatial framework.
} 
Comparing (6) and (7), we see that the sign of $\partial q_{i} / \partial \theta$ is given by the sign of the first term on the left-hand side of (7).

Consider first the special case of purely profit-oriented hospitals (i.e., $\alpha=0$ ). It is evident from (7) that, if an interior solution exists, each hospital will choose a quality level that implies a positive price-cost margin (i.e., $p-\partial c / \partial x_{i}>0$ ). This implies, from $(6)$, that $\partial q_{i} / \partial \theta>0$. Because of continuity, this result holds also for sufficiently small values of $\alpha$. Thus, if the degree of altruism is sufficiently low, competition leads to higher quality. ${ }^{12}$ The intuition behind this result is straightforward. If the marginal patient is profitable to treat, a sufficiently profit-oriented hospital will react to competition (which implies a more quality-elastic demand) by increasing quality in order to attract more patients.

However, a sufficiently high degree of altruism might introduce a counteracting incentive. All else equal, altruism stimulates incentives for quality provision. This creates not only a larger scope for the existence of an interior-solution equilibrium, but it also creates a scope for an interior solution with a negative price-cost margin (i.e., $p-\partial c / \partial x_{i}<0$ ). In this case, competition has two counteracting effects on the incentives for quality provision. On the one hand, hospitals have an incentive to 'compete' to avoid treating unprofitable patients (since $p-\partial c / \partial x_{i}<0$ ), implying lower quality. On the other hand, the presence of semi-altruistic preferences creates an incentive for 'altruistic competition' to treat more patients, implying higher quality. Overall, competition will lead to lower quality provision in equilibrium if the former effect is stronger than the latter. From (6)-(7) we see that the scope for a negative relationship between competition and quality (i.e., $\left.\partial q_{i} / \partial \theta<0\right)$ is larger if $p$ is relatively low, and if $\partial B_{i} / \partial q_{i}$ is large relative to $\partial B_{i} / \partial x_{i}$ (i.e., if the hospitals care more about the quality offered to patients than about the number of patients treated).

\footnotetext{
${ }^{12}$ Alternatively, if an interior solution does not exist, i.e., if

$$
\left(p-\frac{\partial c}{\partial x_{i}}+\alpha \frac{\partial B_{i}}{\partial x_{i}}\right) \frac{\partial x_{i}}{\partial q_{i}}+\alpha \frac{\partial B_{i}}{\partial q_{i}}<\frac{\partial c}{\partial q_{i}}
$$

for all $q_{i} \geq \underline{q}$, each hospital will choose quality at the minimum level and (a marginal increase in) competition has no effect on equilibrium quality provision.
} 


\subsection{Competition and cost efficiency}

The effect of increased patient choice on equilibrium cost efficiency is given by (once more, see Appendix A for details):

$$
\frac{\partial e_{i}}{\partial \theta}>(<) 0 \quad \text { if } \quad \frac{\partial F_{e}}{\partial q_{i}} \frac{\partial q_{i}}{\partial \theta}>(<) 0
$$

Thus, under the condition $\partial F_{e} / \partial q_{i}>0$, competition leads to higher (lower) cost efficiency if it also leads to higher (lower) quality provision. The condition $\partial F_{e} / \partial q_{i}>0$ requires that either (i) higher quality provision leads to higher total demand for hospital treatment, i.e., $\partial\left(x_{i}+x_{j}\right) / \partial q_{i}>0$, or (ii) more cost-containment effort reduces the marginal cost of quality provision for a given treatment volume, i.e., $\partial^{2} c / \partial e_{i} \partial q_{i}<0$.

If (i) holds, a positive relationship between competition and quality provision implies that competition also leads to a higher treatment volume at each hospital, which gives each hospital a stronger incentive to increase the profit margin by reducing marginal treatment costs. If (ii) holds, a positive relationship between competition and quality provision also gives each hospital a stronger incentive to reduce the marginal cost of quality provision through cost-containment effort. Obviously, the logic is reversed for the case of a negative relationship between competition and quality provision. Thus, if (i) and/or (ii) hold, quality and cost-containment efforts are complementary strategies for each hospital. On the other hand, if total demand for hospital treatment is fixed and if it is not possible to reduce the marginal cost of quality provision through cost-containment effort, then competition has no effect on hospital cost efficiency.

\section{Institutional background and NHS reforms}

Norway has a mandatory health insurance scheme provided by the government and financed through general taxation. Almost all health care is provided by the National Health Service (NHS) with only a very limited private provision alongside. Primary care is provided by publicly funded physicians, so-called general practitioners (GPs), that are gatekeepers, implying that patients need a referral to access secondary care. Secondary care is provided by NHS hospitals. During our analysis period from 1998 to 2005, we have in total 64 NHS hospitals with 58 being public and 6 private non-profit. Figure 1 shows the geographical distribution of the 64 hospitals in the Norwegian NHS, revealing substantial variation in the density of hospitals across the country, with highest (lowest) hospital 
density in South-Eastern (Northern) Norway.

[ Figure 1 here ]

The NHS hospitals are funded by a combination of block grants and fixed prices per patient (treatment). The block grant payment is a sort of capitation scheme (risk-adjusted fixed payment per inhabitant in each health region), whereas the fixed prices are based on the diagnosis related groups (DRG) system. The mixed funding scheme, which was introduced in 1997 in the Norwegian NHS, implies that the fixed DRG prices are cut according to the relative share of block grant and fixed price funding. During the analysis period, the share of the fixed DRG price funding fluctuates between 40 to 60 percent, as shown in Figure 2. Thus, the NHS hospitals receive between 40 to 60 percent of the fixed treatment prices, which are set equal to the average cost across NHS hospitals within each DRG, during this period.

\section{[ Figure 2 here ]}

Health care within the NHS is almost free at the point of use. For hospital care, there are virtually no patient copayments. For primary care, patients are charged copayments, but only up to an annual expenditure cap, which was less than NOK 2000 (about $£ 200$ or $\$ 250$ ) during the period 1998 to 2005. After the cap is reached, there is 100 percent insurance coverage for all additional copayments. However, as is common in NHS systems, access to secondary care is rationed through waiting lists.

Motivated by large differences in waiting times across geographical regions, the Norwegian government introduced a patient choice reform in the NHS in 2001, replacing an administrative system where GPs automatically referred patients to the closest hospital offering the relevant treatment within their county of residence. The reform changed this system drastically, as patients were entitled with the right to choose among all NHS hospitals across the whole of Norway for elective (non-acute) treatments. Since Norway is a country with large geographical distances, the government also allowed for reimbursement of travel expenditures to stimulate the exercise of patient choice within the NHS. A patient choice website was also set up with information on quality indicators and waiting times, so that patients (or their GPs) could make informed hospital choices.

Following the patient choice reform, the public hospitals were corporatised into so-called stateowned health enterprises, and ownership was transferred from the counties to the state. The 
motivations behind this ownership reform, which was implemented in 2002, were mainly to enforce harder budgets and reduce the political influence on the governance of the public hospitals. The public hospitals were also given more financial autonomy, including the possibility of transferring surpluses (or deficits) across years. Norway was also divided into five health regions, each with a regional health authority governing the provision hospital care within their region, which had previously been done by 19 county administrations prior to the reform. Thus, public hospitals were given more autonomy and financial flexibility, which could make them more responsive to patient choice, as gain (loss) of patients would increase (reduce) revenues. Notably, the reforms in the Norwegian NHS have clear parallels to the reforms in the English NHS studied by Cooper et al. (2011) and Gaynor et al. (2013), which allow for comparison of results.

\section{$5 \quad$ Data and descriptive statistics}

To analyse the effects of exposing NHS hospitals to competition, we have assembled a rich database with panel information at the hospital and DRG level on a wide set of variables, including mortality, readmission, length of stay, hospital characteristics, patient characteristics, etc. The primary data source is the Norwegian Patient Registry (NPR), which covers the universe of hospital episodes in the Norwegian NHS. ${ }^{13}$ From this registry we have obtained detailed patient level information for a period of eight years from 1998 to 2005. For each hospital episode, we observe a set of patient characteristics (age, gender, comorbidities, municipality of residence, etc.), treatment characteristics (date of admission, diagnosis, DRG, emergency or elective, regular admission or readmission, etc.), and hospital characteristics (university, regional or local hospital, address, ownership status, etc.).

Since the data include patient and hospital identifiers, we can compute travel distances and patient flows by using a distance matrix containing information in terms of kilometers and travel time. All hospitals in our sample provide emergency treatments, leaving us with a sample of 64 hospitals of which 58 are public hospitals and 6 are private non-profit hospitals. However, for the analysis of AMI and stroke mortality, we exclude hospitals with very few patients in order to avoid the problem of variability of rates from small denominators, reducing our sample to 61 hospitals. The data are aggregated such that the unit of observation is at hospital level per quarter

\footnotetext{
${ }^{13}$ More information is available on the webpage of the Norwegian Directorate of Health: https://helsedirektoratet.no/english/norwegian-patient-registry
} 
for mortality and hospital-DRG level per quarter for readmission and length of stay.

[ Table 1 here ]

Table 1 presents the summary statistics of all variables used in the regressions. The hospitals in our sample have an average length of stay of 5.2 and 5.9 days for elective and emergency patients, respectively. 12.8 percent of elective patients are readmitted to the hospitals, whereas the equivalent figure for emergency patients is 16.1 percent. Patients receiving emergency (elective) treatment are on average 58.8 (57.3) years old, 48.6 (49.8) percent of them are men, and they have on average 1.3 (1.1) comorbidities. Thus, emergency patients appear to be slightly more severe than elective patients.

The average hospital in our sample has an overall mortality rate of 3 percent, AMI mortality rate of 14 percent, and stroke mortality rate of 13.1 percent. These are in-hospital mortality rates. Unfortunately, information on post-hospital discharge mortality rates (e.g., 30 day AMI mortality rate) was not available during our sample period. However, most studies do find similar effects for both in-hospital and after discharge mortality rates. ${ }^{14}$ Finally, the Hirschman-Herfindahl Index (HHI) for the average hospital in our sample indicates a fairly high degree of market concentration with actual and predicted HHIs at the levels of 4532 and 3707, respectively. The HHIs are based on patient flows and computed using the approach by Kessler and McClellan (2000), which we describe in detail in the next section.

To get a first glimpse of the possible effects of exposing NHS hospitals in Norway to competition, we split hospitals according to whether they are above or below the median (predicted) HHI in the sample, and compare the change in the means of our dependent variables before and after the patient choice reform. The descriptive statistics of this decomposition are reported in Table 2.

\section{[ Table 2 here ]}

The average travelling distance increases considerably more, both in absolute and relative terms, for patients being treated in hospitals with an HHI below the median. This indicates that patient choice is exercised to a larger extent in less concentrated markets, and is therefore a reassuring indication of the validity of using the HHI as measure of the scope for competition, as we explain more elaborately in Section 6.

\footnotetext{
${ }^{14}$ See, for instance, Kessler and McClellan (2000) and Gaynor et al. (2013).
} 
Regarding changes in our dependent variables, Table 2 shows that hospitals with an HHI below the median tend to have a sharper reduction in mortality rates than hospitals with an HHI above the median. This tendency is consistent across all three mortality measures. A similar picture emerges for the length of stay for elective admissions, where the reduction is larger for hospitals with an HHI below the median. For readmission rates, on the other hand, the opposite tendency occurs, with relatively stronger reductions for hospitals with and HHI above the median, making the overall picture somewhat mixed. It remains to be seen, though, whether it is possible to establish any causal relationships. This is explored in the next section, where we explain our empirical strategy to identify the effects of exposing NHS hospitals to (non-price) competition, and report the results from our estimations.

\section{Empirical strategy}

To estimate the effects of competition on hospitals' provision of care, we exploit a policy reform introducing nation-wide patient choice in Norway in January 2001 for elective (non-acute) treatments. After the reform, patients (or the GPs acting as the patients' agent) can choose among any NHS hospital in Norway, depending on their preferences regarding location, quality, waiting time, etc. Since prices are regulated and copayments are basically zero for hospital care within the NHS, the patient choice reform possibly induces non-price competition among the NHS hospitals in Norway.

Based on the theoretical analysis in Section 3, we predict that the introduction of (or simply harder) non-price competition induces hospitals to improve their quality of care if they are sufficiently profit oriented and face a positive price-cost margin (i.e., the regulated DRG price exceeds the marginal cost). However, if hospitals are sufficiently patient utility oriented (altruistic), the effect of competition is generally ambiguous. Indeed, in the case of a negative price-cost margin, the introduction of competition may have adverse effects on hospitals' incentives to improve quality of care. We also identify a positive relationship between quality and cost-containment effort, implying that the effect of competition on hospitals' cost efficiency is qualitatively similar to the effect on quality. The predictions from the theoretical analysis in Section 3 can therefore be summarised as in Table 3.

[ Table 3 here ] 
The majority of hospitals in the Norwegian NHS have public ownership, which makes it less obvious that profit maximisation is their key objective. Moreover, the mixed hospital payment scheme with partly block grant funding implies a significant cut in the DRG prices (around 50 percent), which may result in negative price-cost margins, especially if hospitals operate close to their capacity limits. These observations suggest, according to our theoretical predictions, that the effect of introducing competition in the Norwegian NHS is an open, and indeed empirical, question.

Our empirical strategy to identify the effects of competition on hospitals' provision of care builds on the work by Cooper et al. (2011) and Gaynor et al. (2013). The idea is simply that while the treatment (i.e., the reform introducing competition) is common to all NHS hospitals, the intensity of the treatment (i.e., the scope for competition) varies significantly across geographical regions depending on the distribution of patients and hospitals. This feature facilitates a difference-indifference (DiD) approach, where the effects of competition are identified by using hospitals located in areas with limited or no scope for competition as the counterfactual.

A key issue, though, is to obtain a treatment (or competition) intensity measure for each hospital. We follow the approach taken by Kessler and McClellan (2000) by estimating a predicted HHI for each hospital based on individual patient flow information. This approach is also adopted by Cooper et al. (2011) and Gaynor et al. (2013). A key difference in their approaches is that Cooper et al. (2011) use instantaneous HHIs based on patient flows in each period both before and after the English patient choice reform, whereas Gaynor et al. (2013) use only pre-reform HHIs based on patient flows for a given year prior to the reform. As patient flows after the reform are likely to depend on quality differences between hospitals, we take the same approach as Gaynor et al. (2013) in order to avoid reverse causality bias when estimating the effects of hospital competition. In Appendix B we provide a detailed description of our estimation strategy for the hospital concentration measures.

We apply a DiD approach to estimate the effect of competition on hospitals' care provision, where the intensity of the treatment is captured by the interaction of the predicted pre-reform HHIs (specific for each hospital) and a post-reform dummy (common to all hospitals). The predicted pre-reform HHIs are treatment intensity measures, reflecting the level of competition each hospital is facing after the reform. We estimate the following DiD regression model

$$
Y_{h d t}=\gamma_{h d}+\lambda_{t}+\delta\left(D_{t} * H H I_{h}\right)+X_{h d t}^{\prime} \beta+\varepsilon_{h d t},
$$


where $h$ denotes the hospital, $d$ the DRG and $t$ the quarter. $Y_{h d t}$ is the dependent variable of interest, which is either readmission rates, mortality rates (AMI, stroke, and overall), or length of stay. All the outcomes variables are log-transformed. $D_{t}$ is a post-reform dummy taking the value 1 for all periods after the reform was implemented in January 2001 and 0 otherwise. $H H I_{h}$ is the logarithm of the predicted pre-reform HHIs specific for each hospital. We interact this concentration measure with the post-reform dummy. Thus, $\delta$ is the DiD coefficient capturing the effect of introducing competition among the NHS hospitals and can be interpreted as an elasticity. In the regression, we also include hospital-DRG fixed effects $\left(\gamma_{h d}\right)$ that control for hospital and treatment specific unobserved heterogeneity which are invariant over time. This implies that the effects of competition are estimated using only within hospital and DRG variation over time in our outcome variables. For overall mortality, we include only hospital fixed effects due to very low (often zero) mortality rates for many of the DRGs. For AMI and stroke mortality, we exclude hospitals that treat less than three patients in each quarter. The regression model also includes time dummies $\left(\lambda_{t}\right)$, one for each quarter in each year, to control for time trends in our outcome variables, and a vector of observed characteristics $\left(X_{h d t}\right)$ of each hospital's patient population over time (average age, proportion of male patients and comorbidity at DRG level) to control for patient casemix. Finally, $\varepsilon_{h d t}$ is random noise.

\section{Results}

In this section we report the results from our empirical analysis on the impact of hospital quality and cost efficiency. Towards the end of the section, we also report results on whether hospital ownership matters by exploring differential effects of competition on public and private (non-profit) hospitals.

\subsection{Hospital quality}

Hospital quality is measured by both mortality and readmission rates, where a reduction in mortality and readmission rates indicates higher quality. For mortality, we use mortality rates for AMI and stroke, which are acute illnesses with a non-negligible chance of death, as well as overall mortality rates. While mortality rates are measured at the hospital level, readmissions are measured at the hospital-DRG level, as explained above. We also estimate the effects on readmission rates separately for acute and elective treatments. The former is less exposed to endogeneity issues 
related to changes in the patient population induced by the patient choice reform. This is also a main argument for focusing on AMI and stroke mortality.

\section{[ Table 4 here ]}

Table 4 reports our DiD estimates of the impact of exposing NHS hospitals to competition on hospital quality measured by (in-hospital) mortality rates. The estimates control for time trends, patient population characteristics, and hospital fixed effects. The first column presents the estimates for stroke mortality, the second for AMI mortality, and the third for overall hospital mortality. While the point estimates of the DiD coefficients are positive for all three mortality measures, the effect is statistically significant (at 1\% level) only for AMI mortality. The DiD coefficient implies that a 10 percent fall (i.e., a 370 points reduction from the mean) in the predicted HHI is associated with a 2.82 percent fall in the AMI mortality. This amounts to a reduction of 0.39 percentage points at the mean AMI mortality rate of 14 percent in the sample. In other words, a 10 percent fall in the HHI implies that one additional life is saved per 500 AMI admissions.

These findings are in line with Cooper et al. (2011) and Gaynor et al. (2013), and are even very comparable in magnitude. For example, Gaynor et al. (2013) find that a 10 percent reduction in the HHI leads to a 2.91 percent drop in the AMI mortality rate, which is very close to our estimate. $^{15}$ This is perhaps surprising, since the institutional differences suggest that incentives for competition in the Norwegian NHS might be weaker than in the English NHS, because of the mixed payment scheme (implying a lower DRG price) and generally longer travel distances. When considering all three mortality measures, we do not find any adverse quality effects of exposing the NHS hospitals to competition.

According to our theoretical analysis, the above described findings indicate either that the Norwegian hospitals are profit-oriented and face non-negative price-cost margins, or, if price-cost margins are negative, that the hospitals' altruistic incentives to compete for patients are not outweighed by their financial incentives to avoid attracting patients that are unprofitable to treat.

\section{[ Table 5 here ]}

Table 5 reports our DiD estimates of the effect of competition on hospital readmission rates. The estimates control for time trends, patient population characteristics, and hospital-DRG fixed

\footnotetext{
${ }^{15}$ The mortality definition is slightly different, though, since Gaynor et al. (2013) use 30-day mortality rates. They also report a significantly positive DiD estimate for overall mortality, but the coefficient is very small.
} 
effects. The first column presents the estimates for readmissions for elective treatments, whereas the second column presents the estimates for emergency treatments, which are less likely to be prone to selection issues due to changes in patient flows after the policy reform.

Contrary to what is suggested by the descriptive statistics in Table 2, the DiD coefficients indicate a positive and significant effect of market concentration on both emergency and elective readmission rates, though the magnitude of the effect differs between the two measures. The estimated coefficients imply that a 10 percent fall in a hospital's predicted HHI on average results in a 7.8 (1.3) percent fall in the emergency (elective) readmission rate. At the sample average these changes correspond to a 1.3 (0.2) percentage point reduction in the emergency (elective) readmission rates. Put differently, a 10 percent fall in the HHI leads to one less readmission per 77 (500) emergency (elective) admissions. These findings indicate that exposing the NHS hospitals to (stronger) competition reduces the underlying risk of being readmitted, which is an indicator of better hospital quality. Unlike the case of AMI mortality, the effects on readmission rates are identified by variation within hospital and DRG.

\subsection{Hospital cost efficiency}

We also examine whether the pro-competition reform had any impact on hospital cost efficiency measured by mean length of stay. While competition may not have a direct impact on incentives to expend effort on reducing treatment costs, there may be indirect effects through the impact of competition on quality, as described in Section 3. In particular, the incentive to improve cost efficiency and thus the profit margin is increasing in a hospital's demand, which implies that quality and cost-containment incentives are complementary strategies. Thus, to the extent that competition induces higher quality and in turn demand, we expect to find a negative effect on (mean) length of stay.

\section{[ Table 6 here ]}

Table 6 reports our DiD estimates of the effect of competition on hospital cost efficiency measured by mean length of stay. The estimates control for time trends, patient population characteristics, and hospital-DRG fixed effects. The first column presents the estimates for mean length of stay for elective treatments, whereas the second column presents the estimates for mean length of stay for emergency treatments, which are less likely to be endogenous due to changes in patient 
flows after the reform. The DiD coefficients are positive and significant for both elective and emergency treatments, with the effect being markedly stronger for elective treatments. The estimates imply that a 10 percent fall in the HHI on average results in a 0.4 (1.6) percent fall in the mean length of stay for emergency (elective) treatments. At the mean length of stay in the sample of 5.9 (5.2) days for emergency (elective) treatments, this implies that one in every 46 (12) patients in these respective categories is discharged one day earlier.

\subsection{Public versus private hospital ownership}

Finally, we examine whether hospital ownership matters for the effects of the pro-competition reform in the Norwegian NHS. In particular, we analyse whether private (non-profit) hospitals in the NHS respond differently to competition than their public counterparts. There are only six private non-profit hospitals in the NHS in the period, so the results need to be interpreted with some caution. To analyse the potential ownership effect, we estimate the following regression model:

$$
Y_{h d t}=\gamma_{h d}+\lambda_{t}+\delta\left(D_{t} * H H I_{h}\right)+\theta\left(D_{t} * P_{h}\right)+\phi\left(D_{t} * H H I_{h} * P_{h}\right)+\beta X_{h d t}^{\prime}+\varepsilon_{h d t},
$$

where $P_{h}$ is a dummy variable taking value one if the hospital is private and zero otherwise (it is equal to one in 9,983 observations). ${ }^{16} \phi$ is the coefficient capturing the differential ownership effect of exposing hospitals to competition, where the ownership dummy is interacted with the reform dummy and the pre-reform HHIs for each hospital. The results from these estimations are presented in Table 7, where the estimates of the key coefficients with respect to mortality, readmission and length of stay are displayed in Panels A, B and C, respectively.

\section{[ Table 7 here ]}

The only dimension along which hospital ownership clearly seems to make a significant difference is cost efficiency. Although increased competition leads to a significant reduction in the average length of stay for the whole population of hospitals, the effect is considerably stronger for private hospitals, and this difference is statistically highly significant for both elective and emergency admissions. In fact, for the latter type of admission, the overall effect of competition, which is admittedly quite low, seems to be largely driven by the response of the private hospitals.

\footnotetext{
${ }^{16}$ One of the six private hospitals changed ownership and became public in 2003 (Orkdal hospital). For this hospital, the dummy $P$ takes the value 1 only until December 2002.
} 
For the other variables where we find significant effects in our main analysis, namely AMI mortality and (elective and emergency) readmissions, private hospitals do not seem to respond significantly different from the public hospitals, though the point estimates have a positive sign. Overall, our results indicate that both public and private (non-profit) hospitals respond to competition by improving quality and cost efficiency, with the private hospitals being more responsive with respect to cost efficiency. According to our theoretical analysis, this can be explained by stronger profit motivation and/or higher price-cost margins.

\section{Concluding remarks}

We have studied the impact of introducing (non-price) competition among hospitals in the NHS on the provision of care. Our empirical analysis exploits a policy reform that implemented nationwide patient choice in the Norwegian NHS in 2001, replacing an administrative scheme where patients were allocated to the closest hospital within their county of residence. The reform facilitates a DiD research design due to exogenous variation in the scope for competition based on the geographical distribution of hospitals and patients. To capture this variation in market structure, we compute an HHI for each hospital based on (predicted) patient flows prior to the policy reform using individual patient level data. Using rich administrative data with quarterly information over eight years from 1998 to 2005, we estimate the effects of exposing NHS hospitals in Norway to competition on hospital quality (mortality and readmission) and cost efficiency (length of stay), controlling for time trends, patient population characteristics, and hospital and DRG fixed effects.

The results show that hospitals in more competitive areas have a significantly sharper reduction in AMI mortality rates, readmission rates, and length of stay than hospitals in less competitive areas after the policy reform. The estimates for stroke and overall hospital mortality have the same sign as the estimate for AMI mortality, but these estimates are not statistically significant. We also find some evidence that the private non-profit hospitals within the NHS respond more strongly to competition with respect to cost efficiency. These findings are rationalised in a theoretical model where competition, induced by patient choice, has a generally ambiguous effect, but is more likely to have a positive impact on quality and cost efficiency if hospitals are profit motivated and face a positive price-cost margin. It is therefore noteworthy that we find a pro-competitive effect in the Norwegian NHS, where hospitals are mainly public and the regulated DRG prices are low due to

a mixed funding scheme. Indeed, our results are consistent with findings from a similar reform in 
the English NHS, and the effects are also comparable in magnitude, even if the Norwegian health care system is characterised by lower DRG prices and generally longer travel distances.

While these findings indicate that exposing NHS hospitals to (non-price) competition (through patient choice) saves lives, reduces readmissions, and shortens hospital stays, we would like to stress some limitations of our study. First, while our findings point in the direction that competition is welfare improving, we have not performed a full welfare analysis, which would require detailed information about hospital costs and other factors affecting patient utility, such as health benefits and waiting time. Second, we have only data on in-hospital mortality rates, whereas other studies also have information on mortality rates after hospital discharge (usually 30 days). If hospitals discharge patients in a poorer state when being exposed to competition, improvements in in-hospital mortality rates may be artificially driven by the fact that patients die after being discharged. While we cannot rule out this possibility, there are a several observations that go in the opposite direction, including the reduction in readmissions (complications). Moreover, there are no explicit incentives for hospitals to manipulate their in-hospital mortality rates as a response to competition, since monitoring and rankings in Norway are based on post-hospital (30 days) discharge mortality rates. Importantly, studies that have both in-hospital and post-hospital mortality rates tend to find similar (not opposite) effects of competition on the two measures. Third, our distance measures are based on municipality of residence, and thus more crude than the ones used in the studies from England (defined neighbourhoods) and the US (zip-codes). However, the municipality structure in Norway is highly decentralised, except in some urban areas. Moreover, the geographical distribution of patients and hospitals is such that the majority of patient flows are across rather than within municipalities.

\section{Appendix}

\section{A. Supplementary calculations for the theory model in Section 3}

The Nash equilibrium of the hospital competition game described in Section 3 is given by (4)-(5). We are interested in characterising how more competition (increased patient choice, measured by 
$\theta$ ) affects equilibrium quality provision and cost efficiency. Differentiation of (4)-(5) yields

$$
\left[\begin{array}{cc}
\frac{\partial F_{q}}{\partial q_{i}} & \frac{\partial F_{q}}{\partial e_{i}} \\
\frac{\partial F_{e}}{\partial q_{i}} & \frac{\partial F_{e}}{\partial e_{i}}
\end{array}\right]\left[\begin{array}{c}
d q_{i} \\
d e_{i}
\end{array}\right]+\left[\begin{array}{c}
\frac{\partial F_{q}}{\partial \theta} \\
\frac{\partial F_{e}}{\partial \theta}
\end{array}\right] d \theta=0,
$$

where equilibrium existence requires $\partial F_{q} / \partial q_{i}<0, \partial F_{e} / \partial e_{i}<0$ and $\Delta:=\left(\partial F_{q} / \partial q_{i}\right)\left(\partial F_{e} / \partial e_{i}\right)-$ $\left(\partial F_{e} / \partial q_{i}\right)\left(\partial F_{q} / \partial e_{i}\right)>0$, and where

$$
\begin{gathered}
\frac{\partial F_{q}}{\partial e_{i}}=-\frac{\partial^{2} c}{\partial e_{i} \partial x_{i}} \frac{\partial x_{i}}{\partial q_{i}}-\frac{\partial^{2} c}{\partial e_{i} \partial q_{i}}, \\
\frac{\partial F_{e}}{\partial q_{i}}=-\frac{\partial^{2} c}{\partial x_{i} \partial e_{i}} \frac{\partial\left(x_{i}+x_{j}\right)}{\partial q_{i}}-\frac{\partial^{2} c}{\partial q_{i} \partial e_{i}}, \\
\frac{\partial F_{q}}{\partial \theta}=\left(p-\frac{\partial c}{\partial x_{i}}+\alpha \frac{\partial B_{i}}{\partial x_{i}}\right) \frac{\partial^{2} x_{i}}{\partial \theta \partial q_{i}}
\end{gathered}
$$

and

$$
\frac{\partial F_{e}}{\partial \theta}=0
$$

The symmetry assumption has two implications that that are important for the derivation of (A2)(A5). First, when both hospitals provide the same quality level, patient choice has no direct effect on demand; i.e., $\partial x_{i} / \partial \theta=0$. Second, notice that

$$
\left.\frac{\partial x_{i}}{\partial q_{i}}\right|_{q_{j}=q_{i}}=\frac{\partial x_{i}}{\partial q_{i}}+\left.\frac{\partial x_{i}}{\partial q_{j}}\right|_{q_{j}=q_{i}}=\frac{\partial x_{i}}{\partial q_{i}}+\frac{\partial x_{j}}{\partial q_{i}}=\frac{\partial\left(x_{i}+x_{j}\right)}{\partial q_{i}} .
$$

Applying Cramer's Rule on (A1), the effect of competition on equilibrium quality provision is given by

$$
\frac{\partial q_{i}}{\partial \theta}=\frac{1}{\Delta}\left(\frac{\partial F_{e}}{\partial \theta} \frac{\partial F_{q}}{\partial e_{i}}-\frac{\partial F_{q}}{\partial \theta} \frac{\partial F_{e}}{\partial e_{i}}\right)
$$

Since $\Delta>0, \partial F_{e} / \partial e_{i}<0$ and $\partial F_{e} / \partial \theta=0$, we have

$$
\operatorname{sign}\left(\frac{\partial q_{i}}{\partial \theta}\right)=\operatorname{sign}\left(\frac{\partial F_{q}}{\partial \theta}\right)
$$

Using (A4), we derive the condition given by (6) in Section 3 .

Applying once more Cramer's Rule to (A1), the effect of competition on equilibrium cost- 
containment effort is given by

$$
\frac{\partial e_{i}}{\partial \theta}=\frac{1}{\Delta}\left(\frac{\partial F_{e}}{\partial q_{i}} \frac{\partial F_{q}}{\partial \theta}-\frac{\partial F_{q}}{\partial q_{i}} \frac{\partial F_{e}}{\partial \theta}\right)
$$

Since $\Delta>0$ and $\partial F_{e} / \partial \theta=0$, we have

$$
\operatorname{sign}\left(\frac{\partial e_{i}}{\partial \theta}\right)=\operatorname{sign}\left(\frac{\partial F_{e}}{\partial q_{i}} \frac{\partial F_{q}}{\partial \theta}\right)=\operatorname{sign}\left(\frac{\partial F_{e}}{\partial q_{i}} \frac{\partial q_{i}}{\partial \theta}\right)
$$

which implies the condition given by (8) in Section 3 .

\section{B. Estimation of the hospital concentration measures}

To derive the predicted HHIs for each hospital, we first estimate the probability that Patient $i$ chooses Hospital $h$ out of a total of $H$ hospitals using the following conditional logit model at individual patient level

$$
P_{i h}=\frac{\exp \left(\alpha+\beta k m_{i h}+\beta_{2} k m_{i h}^{2}+\beta_{3} k m_{i h}^{3}++\beta_{4}^{\prime} k m_{i h} \boldsymbol{X}_{\boldsymbol{i}}+\beta_{5}^{\prime} k m_{i h}^{2} \boldsymbol{X}_{\boldsymbol{i}}+\beta_{6}^{\prime} k m_{i h}^{3} \boldsymbol{X}_{\boldsymbol{i}}+a_{h}\right)}{\sum_{l=1}^{h} \exp \left(\alpha+\beta k m_{i h}+\beta_{2} k m_{i h}^{2}+\beta_{3} k m_{i h}^{3}++\beta_{4}^{\prime} k m_{i h} \boldsymbol{X}_{\boldsymbol{i}}+\beta_{5}^{\prime} k m_{i h}^{2} \boldsymbol{X}_{\boldsymbol{i}}+\beta_{6}^{\prime} k m_{i h}^{3} \boldsymbol{X}_{\boldsymbol{i}}+a_{h}\right)},
$$

where $k m_{i h}$ is the distance in kilometers from Patient $i$ 's municipality of residence to the municipality where Hospital $h$ is located. We also include the interactions between distance measures and a vector of patient characteristics (age and gender) denoted by $\boldsymbol{X}_{\boldsymbol{i}}$. In order to control for the size of the hospitals, we include hospital fixed effects $a_{h}$.

Because of the geographic and demographic characteristics of Norway, which is sparsely populated over a long-stretched area, travelling distances can potentially be very long. In such a setting, a potential concern when estimating (B1) is that the model will attribute an unreasonably high probability to choosing a hospital that is located very far away. We therefore restrict the choice set of each patient to the six closest hospitals (and drop observations of patients that are treated by hospitals outside this set). ${ }^{17}$

The estimates are derived using data from 1998, which is our first year of observation prior to the patient choice reform. Some descriptive statistics regarding the geographical patterns of hospital treatment are presented in Table B1. The figures displayed in this table reveal that average travelling distances in the Norwegian hospital market are considerably longer than those in

\footnotetext{
${ }^{17}$ Including all hospitals in each patient's choice set worsens the fit of the model, but leaves our main results qualitatively unaffected. These results are available upon request.
} 
the otherwise comparable UK studies. The table also confirms that the vast majority (more than 90 percent) of the patients were treated at hospitals within our defined choice set.

\section{[ Table B1 here]}

Based on the predicted individual patient choice probabilities, we compute the hospital-specific HHIs following the same two-step procedure as in Cooper et al. (2011) and Gaynor et al. (2013). First, the HHI in each municipality is calculated as the sum of squared patient shares across all hospitals where the residents in the municipality migrates to for all elective care. ${ }^{18}$ Second, the HHI for each hospital is calculated as a weighted average of the HHIs for the municipalities served by the hospital, where the weights are the shares of the hospital's patients that live in each municipality.

[ Figure B1 here ]

Figure B1 displays the kernel densities for the predicted HHIs (based on patient flow data from 1998) and the actual HHIs (based on patient flow data from 1998 to 2005). ${ }^{19}$ The predicted HHIs have a flatter distribution, which is likely due to changes in the actual patient flows induced by hospital competition after the patient choice reform in 2001. Since hospital-specific HHIs based on actual patient flows are likely to be endogenous, we use only HHIs based on predicted patient flows prior to the reform (year 1998) as the treatment (competition) intensity measure in the analysis.

\section{References}

[1] Berta, P., Martini, G., Moscone, F., Vittadini, G., 2016. The association between asymmetric information, hospital competition and quality of healthcare: evidence from Italy. Journal of Royal Statistical Society Series A, 179, 907-926.

[2] Bloom, N., Propper, C., Seiler, S., Van Reenen, J. 2015. The impact of competition on management quality: evidence from public hospitals. The Review of Economic Studies, 82, 457-489.

[3] Brekke, K.R., Siciliani, L., Straume, O.R., 2011. Hospital competition and quality with regulated prices. Scandinavian Journal of Economics, 113, 444-469.

\footnotetext{
${ }^{18}$ Our analysis is based at municipality level, which are larger areas than the defined neighbourhoods in Cooper et al. (2011) and Gaynor et al. (2013) and zip-codes in Kessler and McClellan (2001). However, there are more than 400 municipalities in Norway which implies an average population size of around 45,000 inhabitants.

${ }^{19}$ The correlation between the two measures is 0.47 .
} 
[4] Brekke, K.R., Siciliani, L., Straume, O.R., 2010. Price and quality in spatial competition. Regional Science \& Urban Economics, 40, 471-480.

[5] Burgess, S., Propper, C., Gossage, D., 2008. Competition and quality: evidence from the NHS internal market 1991-9. Economic Journal, 118, 138-170.

[6] Chou, S.-Y., Deily, M.E., Suhui, L., Lu, Y., 2014. Competition and the impact of online hospital report cards. Journal of Health Economics, 34, 42-58.

[7] Colla, C., Bynum, J., Austin, A., Skinner, J., 2016. Hospital competition, quality, and expenditures in the U.S. Medicare population. Working Paper 22826, National Bureau of Economic Research.

[8] Cooper, Z., Gibbons, S., Jones, S., McGuire, A., 2011. Does hospital competition save lives? Evidence from the NHS patient choice reforms. Economic Journal, 121, 228-260.

[9] Cooper, Z., Gibbons, S., Skellern, M., 2016. Does competition from private surgical centres improve public hospitals' performance? Evidence from the English National Health Service. CEPR Discussion Paper No. 1434.

[10] Federal Trade Commission and U.S. Department of Justice. 2004. Improving Health Care: A Dose of Competition. Washington, DC, July.

[11] Feng, Y., Pistollato, M., Charlesworth, A., Devlin, N., Propper, C., Sussex, J., 2015. Journal of Health Services Research \& Policy, 20, 11-17.

[12] Gaynor, M., 2006. What do we know about competition and quality in health care markets? Foundations and Trends in Microeconomics 2 (6).

[13] Gaynor, M., Moreno-Serra, R., Propper, C. 2013. Death by market power: Reform, competition and patient outcomes in the British National Health Service. American Economic Journal: Economic Policy, 5, 134-166.

[14] Gaynor, M., Town, R.J., 2011. Competition in health care markets, In M. Pauly, T. McGuire \& P.P. Barros (Eds.), Handbook of health economics, North-Holland chapter 9, 499-637.

[15] Gowrisankaran, G., Town, R., 2003. Competition, payers, and hospital quality. Health Services Research, 38, 1403-1422. 
[16] Kessler, D., McClellan, M., 2000. Is hospital competition socially wasteful?, Quarterly Journal of Economics, 115, 577-615.

[17] Kessler, D. P., Geppert, J. J., 2005. The effects of competition on variation in the quality and cost of medical care. Journal of Economics and Management Strategy, 14, 575-589.

[18] Moscelli, G., Gravelle, H., Siciliani, L., Santos, R., 2018. Heterogeneous effects of patient choice and hospital competition on mortality. Social Science and Medicine, 216, 50-58.

[19] Mukamel, D., Zwanziger, J., Tomaszewski, K.J., 2001. HMO penetration, competition and risk-adjusted hospital mortality. Health Services Research, 36, 1019-1035.

[20] OECD, 2017. Health at a Glance 2017: OECD Indicators. Available at http://dx.doi.org/10.1787/health_glance-2017-en

[21] Propper, C., Burgess, S., Green, K., 2004. Does competition between hospitals improve the quality of care? Hospital death rates and the NHS internal market. Journal of Public Economics, 88, 1247-1272.

[22] Propper, C., Burgess, S., Gossage, D., 2008. Competition and quality: evidence from the NHS internal market 1991-9. Economic Journal, 118, 138-170.

[23] Shen, Y.-S., 2003. The effect of financial pressure on the quality of care in hospitals. Journal of Health Economics, 22, 243-269.

[24] Tay, A., 2003. Assessing competition in hospital care markets: the importance of accounting for quality differentiation. RAND Journal of Economics, 34, 786-814.

[25] Vogt, W.B., Town, R.J., 2006. How has hospital consolidation affected the price and quality of hospital care? Robert Wood Johnson Foundation Research Synthesis Report 9. Princeton, February. 


\section{Figures and Tables}

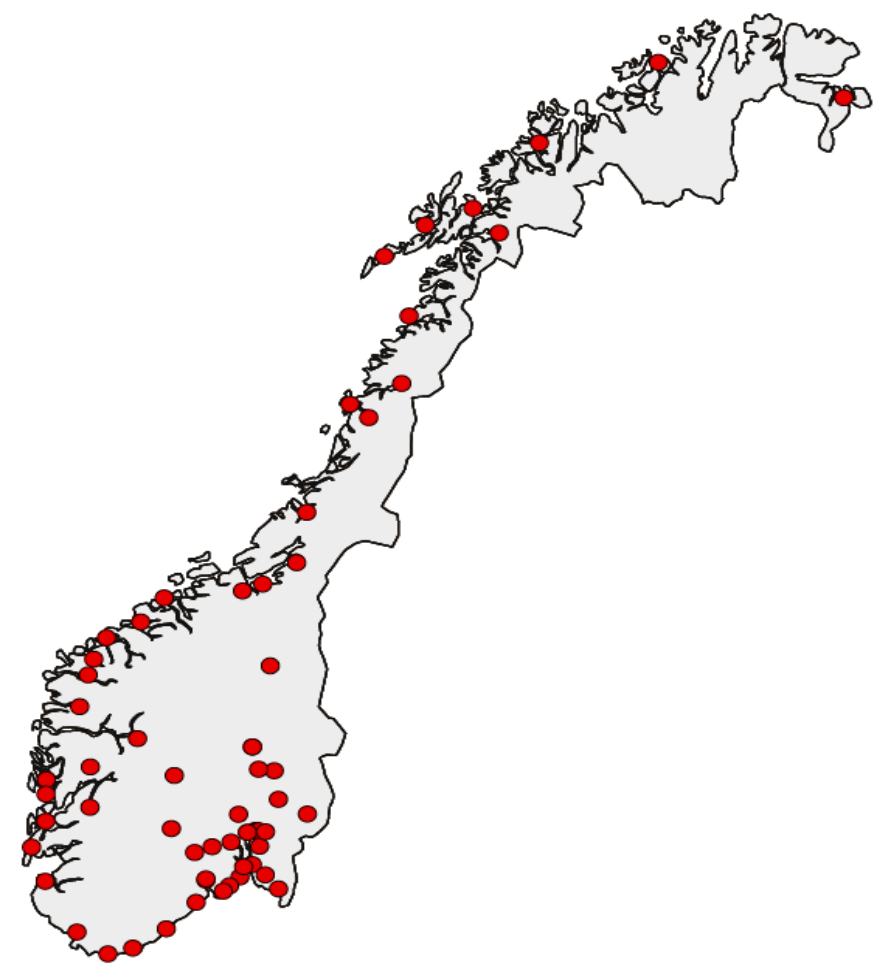

Figure 1. Distribution of NHS hospitals in Norway, $1998-2005$. 


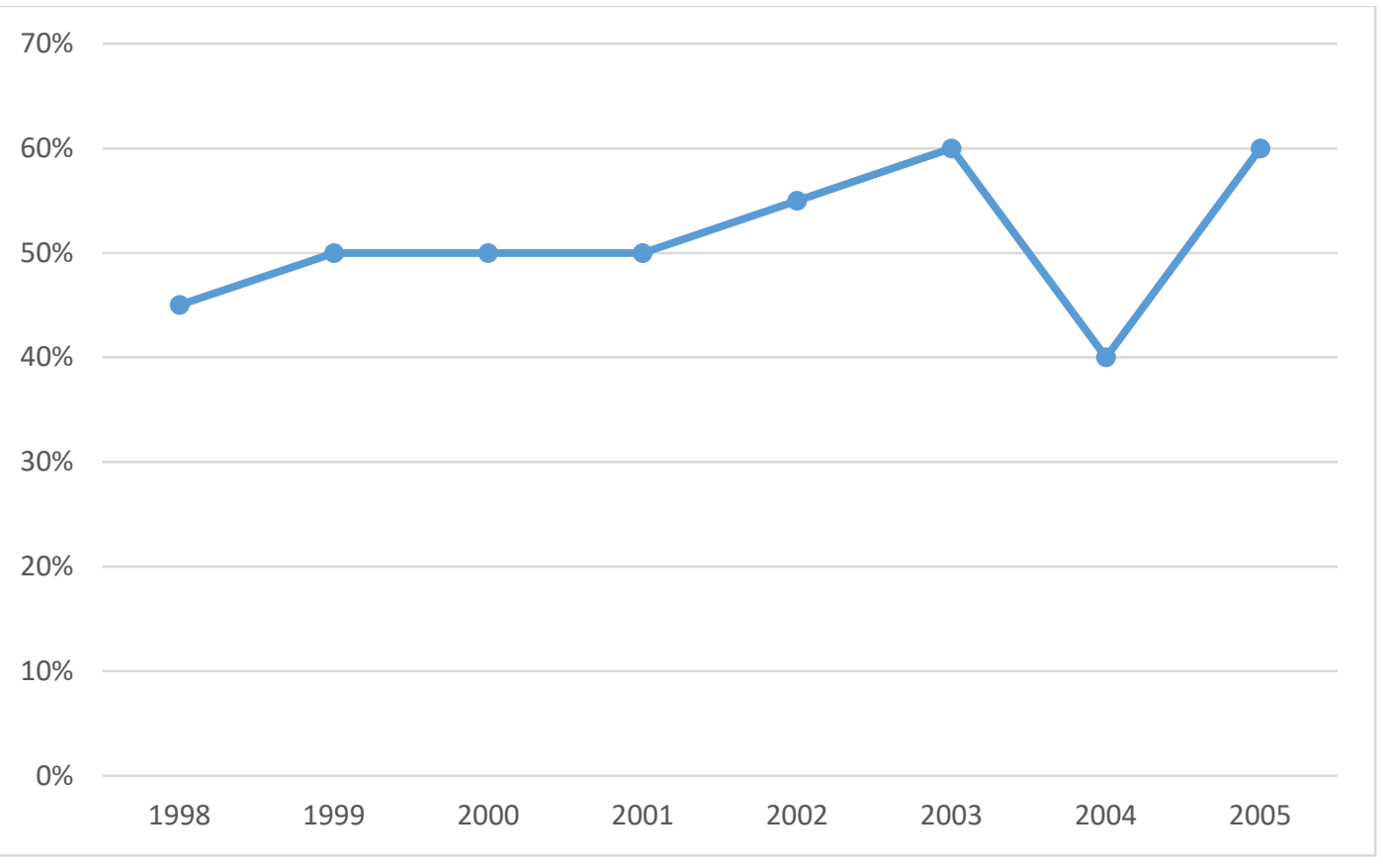

Figure 2. Fixed (DRG) price share of total hospital funding, 1998-2005.

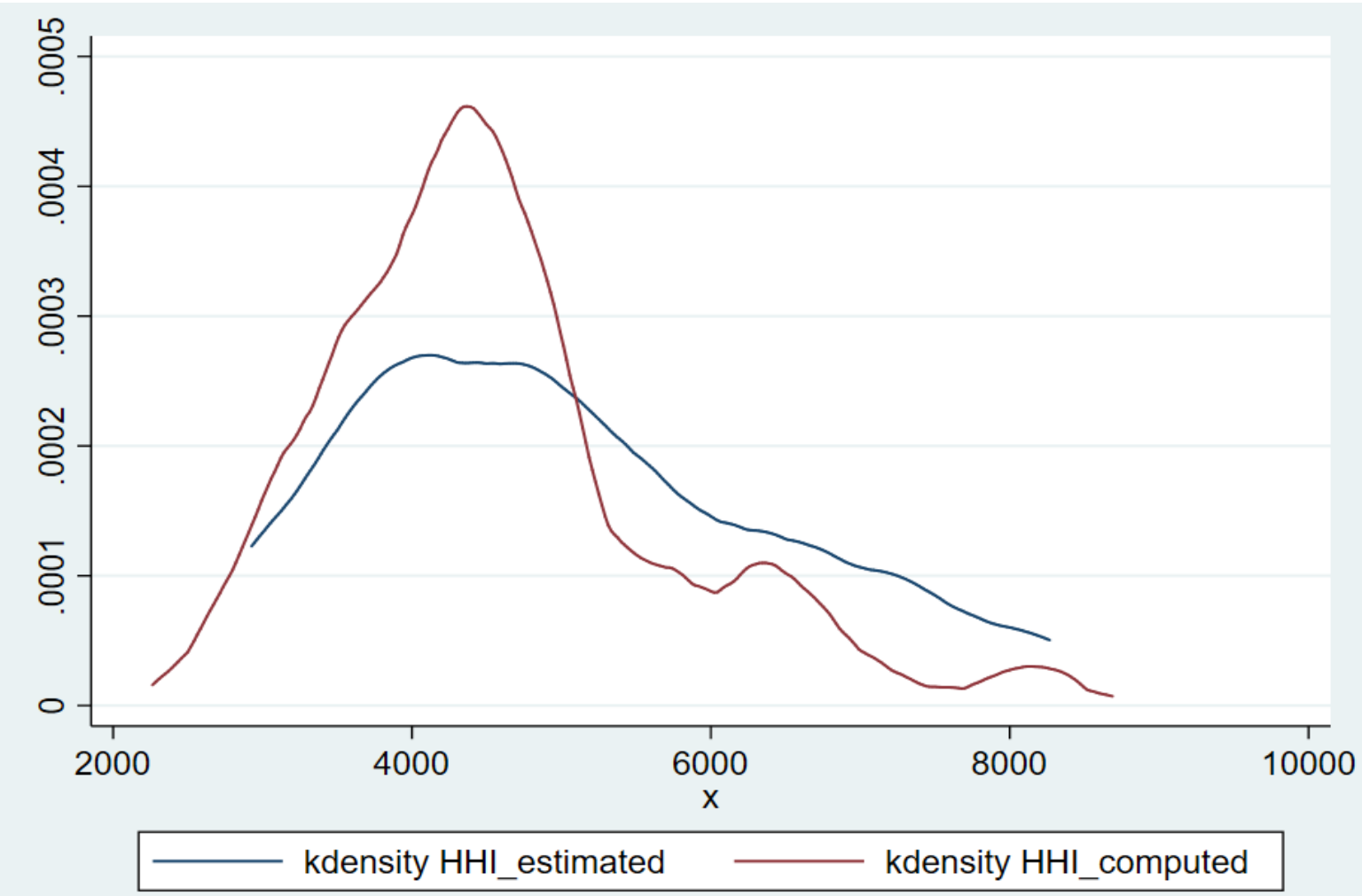

Figure B1. Kernel density estimates for the distribution of actual and predicted HHIs. 
Table 1. Summary statistics

\begin{tabular}{lccccc}
\hline Variable & Mean & $\begin{array}{c}\text { Standard } \\
\text { deviation }\end{array}$ & Minimum & Maximum & $\begin{array}{c}\text { Obser- } \\
\text { vations }\end{array}$ \\
\hline Panel A. Hospital level & & & & & \\
Overall mortality rates & 0.030 & 0.012 & 0 & 0.090 & 1910 \\
AMI mortality rates & 0.140 & 0.074 & 0 & 0.667 & 1752 \\
Stroke mortality rates & 0.131 & 0.074 & 0 & 0.563 & 1765 \\
HHI (actual) & 4,532 & 1,140 & 2262.770 & 8687.340 & 1895 \\
HHI (predicted) & 3,707 & 981 & 2926.681 & 8267.301 & 1910 \\
Total admissions & 5654.892 & 5502.068 & 18 & 19658 & 1910 \\
Elective admissions & 1137.601 & 1117.997 & 14 & 4746 & 1910 \\
AMI admissions & 59.872 & 47.821 & 3 & 293 & 1752 \\
Stroke admissions & 52.948 & 43.129 & 3 & 210 & 1765 \\
& & & & & \\
Panel B. Hospital-DRG level & & & & & 103045 \\
Readmission rates (elective) & 0.128 & 0.242 & 0 & 1 & 146516 \\
Readmission rates (emergency) & 0.161 & 0.208 & 0 & 1 & 103045 \\
Length of stay (elective) & 5.195 & 8.894 & 0 & 2024 & 146516 \\
Length of stay (emergency) & 5.882 & 6.112 & 0 & 951 & 103045 \\
Average age (elective) & 57.267 & 19.477 & 0 & 103 & 146516 \\
Average age (emergency) & 58.831 & 19.792 & 0 & 104 & 103045 \\
Proportion male (elective) & 0.498 & 0.371 & 0 & 1 & 146516 \\
Proportion male (emergency) & 0.486 & 0.303 & 0 & 1 & 7 \\
Average comorbidities (elective) & 1.143 & 1.231 & 0 & 7 & 146516 \\
Average comorbidities (emergency) & 1.334 & 1.153 & 0 & & \\
\hline \hline
\end{tabular}


Table 2. Descriptive changes in dependent variables by market concentration before and after reform

\begin{tabular}{lcccccc}
\hline & \multicolumn{3}{c}{ HHI below median } & \multicolumn{3}{c}{ HHI above median } \\
& Before & After & Change & Before & After & Change \\
\hline Length of stay elective & 6.12 & 4.94 & $-19.3 \%$ & 5.56 & 4.73 & $-14.9 \%$ \\
Length of stay emergency & 6.07 & 5.68 & $-6.4 \%$ & 6.19 & 5.77 & $-6.8 \%$ \\
Readmission rate elective & 0.13 & 0.11 & $-15.4 \%$ & 0.15 & 0.12 & $-20.0 \%$ \\
Readmission rate emergency & 0.16 & 0.15 & $-6.3 \%$ & 0.18 & 0.16 & $-11.1 \%$ \\
Overall mortality rate & 0.034 & 0.029 & $-14.7 \%$ & 0.031 & 0.028 & $-13.3 \%$ \\
AMI mortality rate & 0.167 & 0.125 & $-25.1 \%$ & 0.158 & 0.128 & $-19.0 \%$ \\
Stroke mortality rate & 0.160 & 0.122 & $-23.8 \%$ & 0.140 & 0.117 & $-16.4 \%$ \\
Distance to chosen hospital & 47.947 & 63.537 & $+32.5 \%$ & 91.444 & 97.715 & $+6.9 \%$ \\
\hline \hline
\end{tabular}

Table 3. Predicted effects of hospital competition on quality and cost efficiency

\begin{tabular}{lcc}
\hline \hline & \multicolumn{3}{c}{ Hospital preferences } \\
\cline { 2 - 3 } & Profit oriented & Patient oriented \\
Positive price-cost margin & + & + \\
Negative price-cost margin & 0 & $+/-$ \\
\hline
\end{tabular}


Table 4. DiD estimates of the impact of competition on hospital mortality

\begin{tabular}{|c|c|c|c|}
\hline & $\begin{array}{c}\text { (1) } \\
\text { Mortality stroke }\end{array}$ & $\begin{array}{c}(2) \\
\text { Mortality AMI } \\
\end{array}$ & $\begin{array}{c}(3) \\
\text { Overall mortality }\end{array}$ \\
\hline Reform*HHI & $\begin{array}{c}0.168 \\
(0.162)\end{array}$ & $\begin{array}{l}0.282^{* * *} \\
(0.0796)\end{array}$ & $\begin{array}{c}0.0435 \\
(0.0767)\end{array}$ \\
\hline Average age (emergency) & $\begin{array}{c}0.0224 \\
(0.0158)\end{array}$ & $\begin{array}{c}0.0197^{*} \\
(0.0112)\end{array}$ & $\begin{array}{c}0.0288^{* * *} \\
(0.0103)\end{array}$ \\
\hline Proportion male (emergency) & $\begin{array}{c}0.208 \\
(1.268)\end{array}$ & $\begin{array}{c}0.769 \\
(1.225)\end{array}$ & $\begin{array}{l}0.0845 \\
(0.228)\end{array}$ \\
\hline Av. comorbidity in hospital (emergency) & $\begin{array}{l}-0.127 \\
(0.142)\end{array}$ & $\begin{array}{c}-0.00221 \\
(0.101)\end{array}$ & $\begin{array}{c}0.161^{* *} \\
(0.0656)\end{array}$ \\
\hline Observations & 1,765 & 1,752 & 1,910 \\
\hline$R^{2}$ & 0.058 & 0.076 & 0.230 \\
\hline Number of hospitals & 61 & 61 & 64 \\
\hline Hospital dummies & Yes & Yes & Yes \\
\hline Time dummies & Yes & Yes & Yes \\
\hline
\end{tabular}

Robust standard errors in parentheses. ${ }^{* * *} p<0.01,{ }^{* *} p<0.5,{ }^{*} p<0.1$

Table 5. DiD estimates of the impact of competition on hospital readmissions

\begin{tabular}{lcc}
\hline \hline & $\begin{array}{c}(1) \\
\text { Readmission } \\
\text { (elective) }\end{array}$ & $\begin{array}{c}(2) \\
\text { Readmission } \\
\text { (emergency) }\end{array}$ \\
\hline Reform*HI & $0.128^{* * *}$ & $0.784^{* * *}$ \\
& $(0.0434)$ & $(0.0332)$ \\
Average age & $0.00465^{* * *}$ & $0.00640^{* * *}$ \\
& $(0.000489)$ & $(0.000465)$ \\
Proportion male & 0.0161 & $-0.0311^{*}$ \\
& $(0.0170)$ & $(0.0176)$ \\
Average comorbidities & $0.0455^{* * *}$ & $0.0637^{* * *}$ \\
& $(0.00716)$ & $(0.00713)$ \\
\hline Observations & 102,441 & 145,699 \\
$R^{2}$ & 0.079 & 0.124 \\
Number of hospital-DRGs & 7,536 & 8,054 \\
Hospital-DRG dummies & Yes & Yes \\
Time dummies & Yes & Yes \\
\hline \hline Robust standard errors in parentheses. ${ }^{* * *}{ }^{*}<0.01,{ }^{* *} \mathrm{p}<0.5,{ }^{*} \mathrm{p}<0.1$ &
\end{tabular}


Table 6. DiD estimates of the impact of competition on length of stay

\begin{tabular}{lcc}
\hline \hline & $\begin{array}{c}(1) \\
\text { Length of stay } \\
\text { (elective) }\end{array}$ & $\begin{array}{c}(2) \\
\text { Length of stay } \\
\text { (emergency) }\end{array}$ \\
\hline Reform*HHI & $0.162^{* * *}$ & $0.0370^{* * *}$ \\
& $(0.0303)$ & $(0.0160)$ \\
Average age & $0.00809^{* * *}$ & $0.0109^{* * *}$ \\
& $(0.000449)$ & $(0.000371)$ \\
Proportion male & $-0.132^{* * *}$ & $-0.0581^{* * *}$ \\
& $(0.0132)$ & $(0.0117)$ \\
Average comorbidities & $0.204^{* * *}$ & $0.157^{* * *}$ \\
& $(0.00549)$ & $(0.00454)$ \\
\hline Observations & 102,441 & 145,699 \\
$R^{2}$ & 0.067 & 0.071 \\
Number of hospital-DRGs & 7,536 & 8,054 \\
Hospital-DRG dummies & Yes & Yes \\
Time dummies & Yes & Yes \\
\hline \hline
\end{tabular}

Robust standard errors in parentheses. ${ }^{* * *} p<0.01,{ }^{* *} p<0.5,{ }^{*} p<0.1$ 
Table 7. DiD estimates of the differential ownership impact of competition

\begin{tabular}{lccc} 
Panel A: Mortality rates & & $(1)$ & $(2)$ \\
& Mortality stroke & Mortality AMI & $\begin{array}{c}(3) \\
\text { Overall mortality }\end{array}$ \\
\cline { 2 - 4 } & 0.123 & $0.261^{* * *}$ & $0.147^{* * *}$ \\
Reform*HHI & $(0.174)$ & $(0.0824)$ & $(0.0436)$ \\
Reform*HHI*Private & 0.368 & 0.159 & $-0.451^{*}$ \\
& $(0.343)$ & $(0.190)$ & $(0.233)$ \\
$R^{2}$ & & & 0.250 \\
\hline
\end{tabular}

Panel B: Readmission rates

\begin{tabular}{lcc} 
& $\begin{array}{c}(1) \\
\text { Readmission } \\
\text { (elective) }\end{array}$ & $\begin{array}{c}(2) \\
\text { Readmission } \\
\text { (emergency) }\end{array}$ \\
\cline { 2 - 3 } Reform*HH & $0.174^{* * *}$ & $0.0907^{* * *}$ \\
Reform*HHI*Private & $(0.0452)$ & $(0.0344)$ \\
& 0.154 & 0.0894 \\
$R^{2}$ & $(0.150)$ & $(0.0936)$ \\
\hline
\end{tabular}

Panel C: Length of stay

(1) (2)

Length of stay Length of stay

(elective) (emergency)

$\begin{array}{lcc}\text { Reform*HHI } & 0.108^{* * *} & -0.00139 \\ & (0.0322) & (0.0165) \\ \text { Reform*HHI*Private } & 0.541^{* * *} & 0.357^{* * *} \\ & (0.103) & (0.0547)\end{array}$

$\begin{array}{lll}R^{2} & 0.068 & 0.071\end{array}$

Robust standard errors in parentheses. ${ }^{* * *} p<0.01,{ }^{* *} p<0.5,{ }^{*} p<0.1$. The number of observations and hospitals, and the inclusion of hospital, DRG and time dummies, are identical to the ones reported for the equivalent regressions in Tables 4-7. 
Table B1. Geographical patterns of hospital treatment (1998)

Number of patients

Patients treated at nearest hospital

Patients treated within 6 nearest hospitals

Mean distance to hospital of treatment

Mean distance to closest hospital

Mean distance if hospital is outside 6 nearest
175,341

$52.4 \%$

$91 \%$

73.75

(Std. dev.: 147.28)

24.66

(Std. dev.: 40.64)

313.60

(Std. dev.: 298.24)

Note: Distances in kilometers. 


\section{Most Recent Working Paper}

NIPE WP $\quad$ Brekke, Kurt R., Chiara Canta, Luigi Siciliani e Odd Rune Straume, "Hospital Competition in

19/2018 the National Health Service: Evidence from a Patient Choice Reform", 2018

NIPE WP Paulo Soares Esteves, Miguel Portela e António Rua, "Does domestic demand matter for firms' 18/2018 exports?", 2018

NIPE WP Alexandre, Fernando, Hélder Costa, Miguel Portela e Miguel Rodrigues, "Asymmetric 17/2018 regional dynamics: from bust to recovery", 2018

NIPE WP Sochirca, Elena e Pedro Cunha Neves, "Optimal policies, middle class development and human 16/2018 capital accumulation under elite rivalry", 2018

NIPE WP Vítor Castro e Rodrigo Martins, "Economic and political drivers of the duration of credit

15/2018 booms", 2018

NIPE WP Arash Rezazadeh e Ana Carvalho, "Towards a survival capabilities framework: Lessons from 14/2018 the Portuguese Textile and Clothing industry", 2018

NIPE WP Areal, Nelson e Ana Carvalho, "Shoot-at-will: the effect of mass-shootings on US small gun 13/2018 manufacturers", 2018

NIPE WP Rezazadeh, Arash e Ana Carvalho, "A value-based approach to business model innovation:

12/2018 Defining the elements of the concept", 2018

NIPE WP Carvalho, Ana e Joaquim Silva, "The Work Preferences of Portuguese Millennials - a Survey of 11/2018 University Students", 2018

NIPE WP Souza, Maria de Fátima e Ana Carvalho, "An Organizational Capacity model for wine 10/2018 cooperatives", 2018

NIPE WP Kurt R. Brekke, Tor Helge Holmås, Karin Monstad e Odd Rune Straume, "How does the type

09/2018 of remuneration affect physician behaviour? Fixed salary versus fee-for-service", 2018

NIPE WP Martins, Susana e Cristina Amado, "Financial Market Contagion and the Sovereign Debt

08/2018 Crisis: A Smooth Transition Approach", 2018

NIPE WP Amado, Cristina, Annastiina Silvennoinen e Timo Teräsvirta, "Models with Multiplicative

07/2018 Decomposition of Conditional Variances and Correlations", 2018

NIPE WP Lisi, Domenico, Luigi Siciliani e Odd Rune Straume, " Hospital Competition under Pay-for-

06/2018 Performance: Quality, Mortality and Readmissions”, 2018

NIPE WP Magalhães, Pedro C. e Luís Aguiar-Conraria, "Procedural Fairness, the Economy, and Support

05/2018 for Political Authorities", 2018

NIPE WP Aguiar-Conraria, Luís, Manuel M. F. Martins e Maria Joana Soares, "Estimating the Taylor

04/2018 Rule in the Time-Frequency Domain", 2018

NIPE WP Sousa, Rita, Elsa Agante, João Cerejeira e Miguel Portela, "EEE fees and the WEEE system -

03/2018 A model of efficiency and income in European countries", 2018

NIPE WP Sochirca, Elena e Francisco José Veiga, "Key determinants of elite rivalry: theoretical insights

02/2018 and empirical evidence", 2018

NIPE WP Siciliani, Luigi e Odd Rune Straume, "Competition and Equity in Health Care Market”, 2018

$01 / 2018$

NIPE WP Aguiar-Conraria, Luís, Maria Joana Soares e Rita Sousa, "California's Carbon Market and

$13 / 2017$

NIPE WP Mustapha Olalekan Ojo, Luís Aguiar-Conraria e Maria Joana Soares, "A time-frequency

12/2017 analysis of the Canadian macroeconomy and the yield curve", 2017.

NIPE WP Sousa, Rita, Adérito Santana e Inês Mourão, "Low-Emission Energy Outlook in a Small Island

11/2017 Developing States - The case of Sao Tome And Principe", 2017

NIPE WP Vareiro, Laurentina, J. Cadima Ribeiro e Paula Remoaldo, “Destination attributes and tourist's

10/2017 satisfaction in a cultural destination", 2017

NIPE WP Amado, Cristina, Annastiina Silvennoinen e Timo Teräsvirta, "Modelling and forecasting

09/2017 WIG20 daily returns", 2017

NIPE WP Almeida, André, Hugo Figueiredo, João Cerejeira, Miguel Portela, Carla Sá e Pedro Teixeira,

08/2017 "Returns to Postgraduate Education in Portugal: Holding on to a Higher Ground?", 2017

NIPE WP Magalhães, P. e Luís Aguiar-Conraria, "Procedural Fairness and Economic Voting", 2017

$07 / 2017$

NIPE WP Veiga, Francisco José e Linda Gonçalves Veiga, "Term limits and voter turnout", 2017

06/2017 
